\title{
Reconstruction of Yi Nationality Sani Dietary Culture under the Background of Tourism Development
}

\author{
Zhao Ying \\ Southwest Minzu University, Chengdu 610000, Sichuan
}

Keywords: Yi nationality; Dietary culture; Tourism development; Reconstruction

\begin{abstract}
Sani diet has exerted a far-reaching influence on social and economic development of Yi nationality in Shilin Yizu Autonomous County (hereinafter referred to as Shilin County) in the history. In recent years, tourist industry has become one of the pillar industries in Shilin County, and Sani diet has evolved during the integration and collision with peripheral touring elements and foreign cultures. In this paper, reconstruction study was carried out on Sani diet, which not only concerns the inheritance and development of Yi nationality Sani culture, but also promotes cultural prosperity, social stability and economic development of the Yi nationality.
\end{abstract}

\section{Introduction}

Sani branch is an important component of the Yi nationality, which is not only a geographic concept, but also a cultural concept. Sani people mainly live in Shilin County, Kunming Province, Yunnan, besides, some of the nationality can be found in Qiubei County of Wenshan City, Luxi County and Mile County. Sani people belong to the Yi ethnic group who claim to be "Ni" and created unique culture that can be distinguished from that in other Yi regions in certain historical period. Sani dietary culture is an important component of the traditional Yi culture in Shilin, its particular production method and inheritance patterns have affected the development of social culture and economy in Shilin Yi regions and it is the wisdom crystallization and history testimony of Shilin Yi nationality.

\section{Introduction of Yi nationality Sani dietary culture and background of the tourism development}

Shilin County is named for the famous Shilin Scenic Area, and tourist industry is one of the local pillar industries. Shilin Scenic Area is the sole karst landform scenic area in the world located in subtropical plateau area, and known as "The first spectacle" and "Shilin Museum". The scenic area is also the first batch Chinese key landscape and famous scenery. In 2007, the "South China Karst" consisting of Yunnan Shilin, Guizhou Libo and Chongqing Wulong was successfully included into the world natural heritage. Yunnan Shilin Scenic Area has also become one of the world's cultural heritages, which brought new opportunities for the development of the tourist industry in Shilin, and made prominent contributions to the county's economic and cultural development. With the progressively increasing number of tourists from home and abroad, the hardware and software facilities of Shilin tourism services have been incrementally improved. The number of hotels and restaurants also increased, which will be bound to exert a certain impact on the local traditional dietary culture. In the current situation of inheritance and alteration of Sani dietary culture, only after scientific reconstruction, will the situation of "the beauty of their beauty, a satisfactory together" of Sani dietary culture under the background of tourism development appear.

\section{Inheritance and modern alteration of Shilin Yi nationality Sani diets under the background of tourism development}

Inheritance. According to the author's survey, the current Sani traditional diets mainly include corn meal, buckwheat meal, pigskin and cabbage soup, fried pumpkin flower, braised chicken and 
preserved meat. Throughout the inheritance of these traditional diets, there's a set of inheritance mechanism suitable for the production and development of the social structure and organization, which enables Sani diets stand the test of time.

The inheritance of Sani dietary culture has been deeply affected by psychological effects and tourism development, and the traditional diet customs have been systematically and intactly reserved. Psychological inheritance is the core and main centre of inheritance form, as well as the most intense, most lasting and most impressive cultural inheritance. The inheritance of Sani dietary culture is subject to the psychological dynamic process of consistent cognitions, emotions and wills, which is mainly manifested in that the intergenerational deep-seated accumulation and propagation of the national ideology have penetrated into living standards, production activities and other fields of Shilin Yi nationality area. Therefore, the psychological effects ensure that Sani dietary culture has been somewhat accepted or rejected in historical development and identity consciousness and been handed down for generations.

With the development of the tourist industry, the traditional Yi nationality Sani dietary culture has suffered some impacts. The family based individual workshops were far from satisfying the needs of tourists, and the emergence of the characteristic Yi nationality catering group compensated for this defect. For example, the Pushilao Nationality Hotel appropriately added modern elements to make the dishes and dish styles diversified based on the reservation of traditional Sani dietary culture, so as to better meet the tastes of tourists. Shilin Sani people combined traditional dietary culture with modern tourism to form a stable, imperceptible operating mechanism for the inheritance of Sani dietary culture.

Modern changes. In the process of inheritance, a culture will have some form or degree changes in essence and content compared with the original version, it can completely disappear, be replaced in some component, incorporate new content, or be melted into other cultures. Dietary culture has been constantly changing during the integrations and collisions between Han culture and Western cultures, Tibetan culture, Naxi culture, Lisu culture and Miao culture. However, on the whole, the preservation of Sani dietary culture can not be separated from Sani people's generations of efforts.

(1) Sani diet has become a link of mutual assistance in Shilin Yi nationality. In the present Shilin Yi area, closed social pattern has been gradually broken and young migrant workers are nothing new; therefore, in annual autumn harvest and spring sowing, a great amount of workforces are needed, which is bound to become the biggest dilemma restricting agricultural development in Shilin Yi area. The new era endowed Sani dietary culture with new contents, for example, the diets in weddings and funerals and traditional festivals coagulate the efforts of generations of Sani people. In addition, the Sani migrant workers will carry traditional diets (e.g., bone ginseng, preserved bean curd, etc.) with them as gifts for friends and for homesickness, which also provides convenience for Sani diets to cater to a wider range of audiences.

(2) New contents have been added to Sani dietary culture. Sani people have a good reputation of gracious hospitality, which is expressed by the medium of traditional diets in weddings and funerals, holiday celebrations and religious beliefs. In the new era, the Yi nationality Sani diet gatherings are mostly themed on the publicity of science and technology, the enhancement of national cohesion and other issues such as the improvement of traditional dishes such as buckwheat rice cakes and tartary buckwheat rice, which plays a role that can not be neglected in the development of Sani dietary culture and the deepening of national identity sense.

(3) Sani dietary culture has presented a diversified development. Before the introduction of tourism development into Shilin, the Yi nationality lived in a relatively uninformed and unified area. The traditional Sani diets are mainly dominated by buckwheat rice, pickles (e.g., bone ginseng, preserved bean curd) and preserved meat. Since the reform and opening up, Shilin tourist industry has gotten a flourish, and traditional Sani diets present a diversified trend to satisfy different tastes of the tourists. The traditional dietary cultural consciousness of people in urban areas and out of the Shilin $\mathrm{Yi}$ area becomes weaker, while the regional consciousness of Sani people intensively living in mountainous and semi mountainous areas becomes increasingly strong. In addition, for people with 
an educational background, the higher the educational level is, the stronger the consciousness will be, and vice versa.

\section{The cultural self-consciousness based evolution and reconstruction of Yi nationality Sani diets}

Inspecting the national culture objectively and dialectically is the internal impetus for the development of the culture. The "cultural self-consciousness" concept put forward by Fei Xiaotong means that people living in certain historical and cultural circle have self-understanding of their own culture and full cognition of the development process and future of the culture, namely, the cultural self-awareness, self reflection and self reconstruction. The concept does not mean cultural regression, redintegration, wholesale westernization or othering, but represents making the best of the both worlds and emphasizes the principal status of culture. For Sani dietary culture, the cultural subjectivity should be emphasized, the cultural independence should be adhered to and the vitality should be maintained, besides, transformation and reconstruction should be carried out complying with the needs of social development, so as to achieve "the beauty of their beauty, a satisfactory together" of Sani dietary culture under the background of tourism development.

Transformation. With the development of Shilin tourism culture, Sani dietary culture has gotten a recovery and become more active. Nowadays, for the sake of healthier development of Sani dietary culture, the defects that hinder era development and go against scientific development should be abandoned, and modernization transformation of Sani dietary culture should be realized.

(1) The modernization transformation of social function. The social function of modern Sani dietary culture can be divided into historical function and realistic function. The historical function includes satisfying the daily needs of Sani people, maintaining and consolidating neighborly relations and carrying forward the historic culture of $\mathrm{Yi}$ nationality. The realistic function contains strengthening social control, keeping order, maintaining the stability of Shilin Yi area and promoting the sustainable development of tourism culture. The reconstruction of Sani dietary culture should not rest on the basis of remodeling historical function, instead, some breakthroughs should be made and modernization transformation should be achieved. The previous outmoded conventions and undesirable customs unsuitable for social development should be abandoned, the restriction of hierarchy on traditional Sani dietary culture should be abolished, and the long-term interests of national community and national members should be insisted and taken as the starting point, so that the Sani dietary culture can be integrated into China's modernization cultural construction.

(2) Modernization transformation of value concepts. The Sani dietary culture contains the social ideology of Shilin Yi area and is one of the organic components of the local superstructure. In the reconstruction of Sani dietary culture, the authenticity of the culture should be protected, and based on this, controllable modern elements should be integrated into the culture for improvement, which shall not change the true features of the culture. Thereinto, there is the protection against insignificance towards the authenticity of the dietary culture due to profit-making. The construction of social order of Sani dietary culture became a pressing task, and the value concept of "humanism" should be injected into Sani dietary culture, namely, strengthening the human-centered value concept in the local people's thinking model. In the individual and communitywide value concepts, realizing the value of Sani dietary culture by blind pursuit of economic interests should be avoided by all means, humanity should be stressed, and conflicts should be adjusted with the attitude of pursuing sustainable development of Sani dietary culture, so as to gradually move into the humanity trajectory of the culture.

Reconstruction. Merit-based reconstruction to shape era character of Sani dietary culture.

In order to keep a foothold in the present context, Sani dietary culture should possess the quality of keeping pace with the times. The reconstruction of dietary culture should be based on the long-standing traditional culture of Shilin to carefully identify the necessity and rationality that conform to the needs of era development and to sublate the unreasonable elements. On the one hand, we should be committed to pursuing the preservation of authenticity of the Sani dietary culture, and include Sani dietary culture into the protection of Shilin traditional culture, such as recalling 
traditional Sani dietary culture in the impression on the background of Ashima, establishing Sani dietary culture museum and shooting relevant documentaries to pursue Sani diets in the impression. On the other hand, the way to accept Sani dietary culture should be innovated. The traditional Sani dish display has already been difficult to be accepted, so the reconstruction should not blindly restore the Sani traditional dishes, but should carry out appropriate improvement, so as to discover new ways generally accepted by modern people. For example, courses about traditional dietary culture and its development can be set up in schools, or public hearing can be carried out to get opinions and suggestions on the development of Sani dietary culture from far-sighted personage in all walks of life.

Global concentration, insisting the nationality of Sani dietary culture

Sani dietary culture is an important part of the global multi-civilization, and it is impracticable for the culture to continue the previous closed, preservative, isolated and helpless development path. Sani dietary culture should absorb from other excellent cultures and carry out effective localized reconstruction, so as to get worldwide recognition. Under the overall background of Shilin tourism development, Sani dietary culture needs to be integrated into the world cultural system, learn from others' strong points to offset its own weakness and be equally treated, so as to realize harmonious and mutual development in interaction. It is worth emphasizing that, in nowadays society, the global concentration strategy does not mean that the traditional national cultures shall be driven to a hopeless situation of extinction, instead, in the process of reconstruction, it is necessary to emphasize the significance of long maintaining of cultural self-consciousness, consciously resisting the unhealthy culture corrosion and adhering to national features based on "cultural self-confidence". For example, Shilin Sani Dietary Culture International Academic Exchange, Shilin Yi International Tourism Festival and other activities can be held regularly, activities such as Yi nationality weddings and Long Street Banquet can be appropriately conducted, the splendid Sani traditional dietary culture can be displayed to the world through the platform establishment, the successful mode of Yunnan ethnic village can be used for reference to establish a Yi nationality Sani dietary culture village, and the tourist industry can be developed by means of culture performance, so as to create green GDP and achieve a win-win situation in the protection and reconstruction of Sani dietary culture, thus enabling the culture to get rid of the stale and bring forth the fresh and go global.

\section{Conclusion}

The evolution and reconstruction of national culture is the need of the times for individual nationality, while for social totality, it is a kind of cultural means to gather national strengths, promote economic development and maintain organic operation of the society. As an important part of Shilin Yi social and cultural development, Sani dietary culture should constantly explore favorable elements that help promote social and cultural development under the background of tourism development and abandon unfavorable elements, which is not only the protection and inheritance of national cultural resources, but also a meritorious deed that benefits generation after generation.

\section{Acknowledgments}

Southwest Minzu University degree building (2017XWD-B0304) phased results.

\section{References}

[1] Yunnan Shilin Chronicles Integration. Shilin Yi Autonomous County Annals Office. Yunnan Nationalities Publishing House.2005:356.

[2] Liu Zhengfa. Educational Anthropology Research on the Inheritance of Liangshan Yi Nationality Clan Culture [M]. Beijing: Minzu University of China Press, 2007. 
[3] Yang Zhengxiang. Rational Thinking on the Revival Phenomenon of Hierarchy Obsession of Yunnan Xiaoliangshan Yi Nationality Clan in the New Era [J]. Nanchang: Science \& Technology Economy Market, 2006 (03), p121-p122.

[4] Wang Jianli, Jiang Minglang. Discussion On Chinese Traditional Sports Cultural Self-consciousness Under the Background of Multi-culture[J]. Xi'an: Sports World, 2009 (09), p38-p39.

[5] Zhang Han. The Evolution and Reconstruction of Liangshan Yi Nationality Clan Culture Under the Background of Multi-culture[J]. Mianyang: Journal of Mianyang Normal University, 2012 (12). 